\title{
Fabrication of Nanostructured Kaolinite Doped Composite Films from Silicone Rubber with Enhanced Properties
}

\author{
Abdullah Muhammad Zakaria ${ }^{1,2}{ }^{(D)}$, Shaikat Chandra Dey ${ }^{1}\left(\mathbb{D}\right.$, Muhammad Mominur Rahman $^{3}{ }^{(0)}$, \\ Mithun Sarker ${ }^{1}\left[\right.$, Md. Ashaduzzaman ${ }^{1}\left[\right.$ and Sayed Md. Shamsuddin ${ }^{1, *(1)}$ \\ 1 Department of Applied Chemistry and Chemical Engineering, Faculty of Engineering and Technology, \\ University of Dhaka, Dhaka 1000, Bangladesh; Abdullah.Muhammad.Zakaria@USherbrooke.ca (A.M.Z.); \\ shaikat@du.ac.bd (S.C.D.); mithun@du.ac.bd (M.S.); azaman01@du.ac.bd (M.A.) \\ 2 Département de Médecine Nucléaire et Radiobiologie, Faculté de Médecine et des Sciences de la Santé, \\ Université de Sherbrooke, Sherbrooke, QC J1H 5N4, Canada \\ 3 Department of Chemistry, Virginia Tech, Blacksburg, VA 24061, USA; mrahman1@vt.edu \\ * Correspondence: sdin@du.ac.bd; Tel.: +1-880-171-6733-298
}

Received: 5 April 2019; Accepted: 8 May 2019; Published: 12 May 2019

\begin{abstract}
Naturally occurring nanomaterials are finding growing interests in tailoring properties of engineering polymers for advanced applications. The objective of this study was to develop environment-friendly nanocomposite films by reinforcing kaolinite nanofillers (1-10 wt $\%)$ in silicone rubber (SR) matrix using a simple solvent casting technique. Kaolinite-reinforced films showed substantial improvement in mechanical (tensile strength, Young's modulus, and elongation at break) and thermal properties at very low filler loading $(5 \mathrm{wt} \%)$. The improvement of solvent resistance nature of the fabricated films was another critical aspect of this study. Unfilled SR film showed $~ 19 \%$ weight loss when immersed in toluene for $4 \mathrm{~h}$ at $25^{\circ} \mathrm{C}$, whereas only $\sim 4 \%$ weight loss was recorded in the case of $5 \%(w / w)$ kaolinite loaded film. Therefore, kaolinite has the potential to bring significant improvement in the properties of SR. This study indicates that there is plenty of room at the bottom for proper utilization of the potential of kaolinite for developing SR-based composite materials for potential applications in many industries, such as textile, household cleaning, construction, electronics, automotive, medical, etc.
\end{abstract}

Keywords: nanomaterials; nanocomposite; reinforcing; kaolinite; silicone rubber; solvent casting

\section{Introduction}

Silicone rubber (SR) has made tremendous contributions towards developing high performance industrial products for a wide range of applications. Due to its excellent physicochemical properties, it has gained special attention by many researchers and has been widely utilized to manufacture various valuable industrial products, such as gaskets, cables, sealants, bioimplants, etc. [1]. The outstanding properties of SR include physiological inertness [1], superior electrical insulation [2], radiation resistance [3], corrosion resistance [4], superior fatigue resistance under extreme temperatures [5], thermal oxidative stability [6], fracture toughness [7], and so on. However, poor mechanical performance limits its application and is a major technological challenge for researchers to develop SR-based products [1]. To address these limitations, nanotechnology might play a potential role since nanotechnology is considered as fascinating and revolutionary technology of the twenty-first century. Polymer nanocomposites (NCPs) are the combination of inorganic functional fillers and polymers, which display unexpected hybrid properties that are synergistically derived from both of the components [8]. Nanoparticles often strongly influence the properties of composites because, in 
comparison with the conventional composites, mixing of phases occurs over a much smaller length scale in NCPs [9]. In the case of NCPs, the large available surface area of nanoparticles provides better interaction between fillers and matrix, which ultimately enhances the level of reinforcement [10].

Numerous trials have been performed by many researchers and their coworkers to improve the inherent physicochemical properties of SR by incorporating filler materials, such as layered silicates (LS) [11-13], graphene [14,15], silica [16], boron nitride [17], carbon nanotubes [18], titania [19], zinc oxide [20], ceria [21], alumina [22], etc. However, the most promising results have been found with NCPs fabricated from LS due to its high available surface area, plate morphology, and exceptionally stable oxide network [23]. The significant aspect ratios of LS with thickness in the order of a nanometer and length and width in the order of 10-1000 nm lead to the dramatic improvement in properties, such as thermal stability, modulus, permeability, flame retardancy, and so on [10]. This improvement in properties with higher aspect ratios is attributed to the better reinforcement of nanolayers [9]. However, compared to other layered materials, clay minerals have received more attention due to their low cost, availability, and non-carcinogenic nature [1,24]. In order to achieve good mechanical properties, traditional fillers (silica and carbon black) are used in large quantities $(>20 \sim 50 \mathrm{wt} \%)$, whereas incorporation of much smaller amount $(<10 \mathrm{wt} \%)$ of layered-clay can provide excellent material properties [25]. The distribution pattern of layered-clay greatly controls the properties of NCPs. For polymer-clay composites, three basic types of dispersion patterns have been reported in the literature [26]. The first type is conventional composites, in which clay tactoids are simply dispersed as a segregated phase. The second type is intercalated structure, in which clay layers are well ordered, but polymer chains are inserted into the clay host gallery. The third type is the exfoliated NCPs, in which individual nanosheets lose their layered stacking and are homogeneously dispersed in the polymer matrix. The best physical properties are achieved in exfoliated NCPs due to large polymer/filler interface [26-28]. However, complete exfoliation is seldom achieved, and there is a mixture of exfoliation and intercalation.

Most of the reported studies on polymer-clay NCPs focused on the modification of hydrophilic clay with organic modifiers to make it compatible with hydrophobic SR matrix. Burnside et al. reported improved mechanical and reduced solvent uptake properties of NCP prepared from organically modified montmorillonite (O-MMT) and polydimethylsiloxane (PDMS) [10]. Similar results have been reported by LeBaron et al. [9]. Kong et al. also reported improved thermal and mechanical properties of O-MMT/SR NCP [26]. Ma et al. reported a new strategy to prepare disorderly exfoliated NCP from surfactant modified MMT and SR [29]. Until now, it is found that there is no literature report on kaolinite-SR NCP. Therefore, in this study, an attempt was taken to fabricate high-performance NCP with improved mechanical, thermal, and chemical properties by doping kaolinite into SR matrix using a facile solvent casting method. Apart from this, NCPs were prepared by direct incorporation of raw kaolinite into the SR matrix without any expensive modification step. It was a major breakthrough of this research. The inherent physicochemical properties of kaolinite have made it a promising candidate for the advancement of nanoscience and nanotechnology. Therefore, environment-friendly, available, and cost-effective kaolinite should receive more attention as nanofiller in the fabrication of high-performance NCPs for advanced applications.

\section{Materials and Methods}

\subsection{Materials}

In this study, the semi-solid SR was used for film formation and was purchased from Shangdong Dayi Chemical Co., Laiyang, China. Kaolinite was used for reinforcing SR film, which was collected from Bangladesh Insulator and Sanitaryware Factory Ltd., Dhaka, Bangladesh. For dissolving SR, toluene was selected as a suitable solvent, which was supplied by Active Fine Chemicals Limited (Dhaka, Bangladesh). In order to investigate the chemical resistance of the prepared films, dimethyl sulfoxide (DMSO), dimethylformamide (DMF), and acetic acid were utilized in this study. These 
solvents were purchased from Merck KGaA (Darmstadt, Germany). All of the chemicals were used without further purification.

\subsection{Methods}

\subsubsection{Preparation of Nanocomposite (NCP) Films}

For the preparation of NCPs, different amount of kaolinite was loaded into SR matrix (Table 1).

Table 1. Nanocomposite (NCP) films fabricated with different filler loading. SR-K = silicone rubber- kaolinite.

\begin{tabular}{ccc}
\hline Film Code & \% Silicone Rubber $(w / w)$ & \% Kaolinite $(w / w)$ \\
\hline SR & 100 & 0 \\
SR-K $_{0.01}$ & 99 & 1 \\
SR-K $_{0.03}$ & 97 & 3 \\
SR-K $_{0.05}$ & 95 & 5 \\
SR-K $_{0.07}$ & 93 & 7 \\
SR-K $_{0.10}$ & 90 & 10 \\
\hline
\end{tabular}

A control SR film was also prepared using the same technique for comparison purpose. At first, SR was completely dissolved in toluene $(10 \mathrm{~mL})$ at room temperature $\left(25^{\circ} \mathrm{C}\right)$, which was immediately followed by the addition of dry and powdered-kaolinite. For homogeneous dispersion, this mixture was agitated by a sonicator for $30 \mathrm{~min}$. The resulting viscous dispersion was immediately transferred to a glass plate, where it was air dried at room temperature $\left(25^{\circ} \mathrm{C}\right)$ for $24 \mathrm{~h}$. During this period, the majority of the toluene molecules escaped from the system providing a suitable environment for dynamic interaction between the filler and the matrix. The air-dried composite was finally cured through heat treatment at $150^{\circ} \mathrm{C}$ for $3 \mathrm{~h}$ to prepare the NCP films. The resultant films were characterized and, subsequently, various properties were measured.

\subsubsection{Characterization of the Fabricated Films}

Fourier transform infrared spectroscopy (FTIR) technique was applied to analyze the surface chemistry of the NCP films. FTIR spectra of the samples were recorded in the wavenumber range of $4000-400 \mathrm{~cm}^{-1}$ (Resolution: $4 \mathrm{~cm}^{-1}$ ) with 30 scans on a FTIR $8400 S$ spectrophotometer (Shimadzu Corporation, Kyoto, Japan). Wide angle X-ray powder diffraction (XRD) technique was applied to investigate the intercalation and/or exfoliation phenomenon of layered-kaolinite. XRD patterns of the samples were produced at room temperature $\left(25^{\circ} \mathrm{C}\right)$ on an x-ray diffractometer (Ultima IV, Rigaku Corporation, Akishima, Japan) equipped with $\mathrm{Cu} \mathrm{K} \alpha$ radiation $(\lambda=0.154 \mathrm{~nm})$ generator operated at $40 \mathrm{kV}$ and $40 \mathrm{~mA}$. The dispersion of kaolinite in the SR matrix was thoroughly investigated by taking a scanning electron microscope (SEM) image on a JEOL JSM-6490LA (Tokyo, Japan), which was operated at an accelerating voltage of $20 \mathrm{kV}$. The working distance for SEM analyses was $10 \mathrm{~mm}$.

\subsubsection{Investigation of Mechanical Performance}

Tensile strength $\left(T_{\mathrm{s}}\right)$ and elongation at break $\left(\mathrm{E}_{\mathrm{b}}\right)$ were measured under ambient conditions by strip

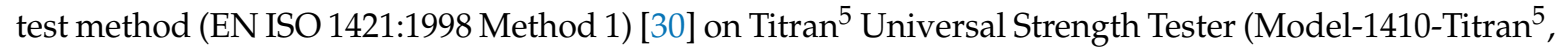
James Heal, Halifax, UK) with an approach speed of $15 \mathrm{~mm} / \mathrm{min}$. The test specimens had the following dimensions: $50 \mathrm{~mm} \times 10 \mathrm{~mm} \times(0.38 \pm 0.02) \mathrm{mm}$. The mechanical properties were tested with five specimens for each composition, and an average was subsequently recorded. All of the specimens were properly conditioned before testing. Young's modulus $\left(\mathrm{Y}_{\mathrm{s}}\right)$ of the samples was finally calculated. 


\subsubsection{Investigation of Thermal Stability}

The thermal stability of unfilled SR and NCP films were thoroughly assessed by recording thermograms on a thermogravimetric analyzer (TGA-50, Shimadzu Corporation, Kyoto, Japan). The specimens $(10 \mathrm{mg})$ were heated from ambient temperature $\left(25^{\circ} \mathrm{C}\right)$ to $800{ }^{\circ} \mathrm{C}$ under dry nitrogen atmosphere (flow rate: $10 \mathrm{~mL} / \mathrm{min}$ ) at a linear heating rate of $10{ }^{\circ} \mathrm{C} / \mathrm{min}$ using alumina cell. All the specimens were kept at $800{ }^{\circ} \mathrm{C}$ for $5 \mathrm{~min}$. The onset degradation temperature/temperature for $10 \%$ mass loss $\left(\mathrm{T}_{\text {onset }} / \mathrm{T}_{10}\right)$, temperature for $50 \%$ mass loss $\left(\mathrm{T}_{50}\right)$, and residue at $800{ }^{\circ} \mathrm{C}\left(\mathrm{R}_{800}\right)$ were recorded.

\subsubsection{Investigation of Chemical Resistance and Swelling Properties}

To investigate the chemical resistance of unfilled SR and NCP films, specimens were carefully cut into rectangular shape and immersed in four different solvents, i.e., water, DMSO, DMF, and acetic acid for $24 \mathrm{~h}$ at $25^{\circ} \mathrm{C}$. After this period, the samples were dried to allow the solvent molecules to evaporate from the specimens. The completely dried specimens were weighed and these weights were compared with the weights before immersion. The degree of swelling was measured by dipping the specimens in toluene for $4 \mathrm{~h}$ at $25^{\circ} \mathrm{C}$. The swelled specimens were gently wiped by tissue paper to remove unabsorbed/adhering toluene followed by immediate weight measurement. The following equation then determined the degree of swelling:

$$
\% \text { Swelling }=\frac{\mathrm{W}_{\mathrm{s}}-\mathrm{W}_{\mathrm{i}}}{\mathrm{W}_{\mathrm{i}}} \times 100,
$$

where, $W_{i}$ is the initial weight of the specimen and $W_{s}$ is the weight of the specimen at maximum solvent uptake.

\section{Results and Discussion}

Facile fabrication of NCPs is crucial from technological point of view. Here, a simple solvent casting technique was used for the preparation of NCP films using SR and kaolinite A simplified scheme is depicted in Figure 1a, which demonstrates various steps involved in the preparation of NCPs. The chemical interaction of kaolinite with SR macromolecules in toluene and the subsequent curing of kaolinite-loaded matrix at $150^{\circ} \mathrm{C}$ resulted in the successful formation of NCPs.

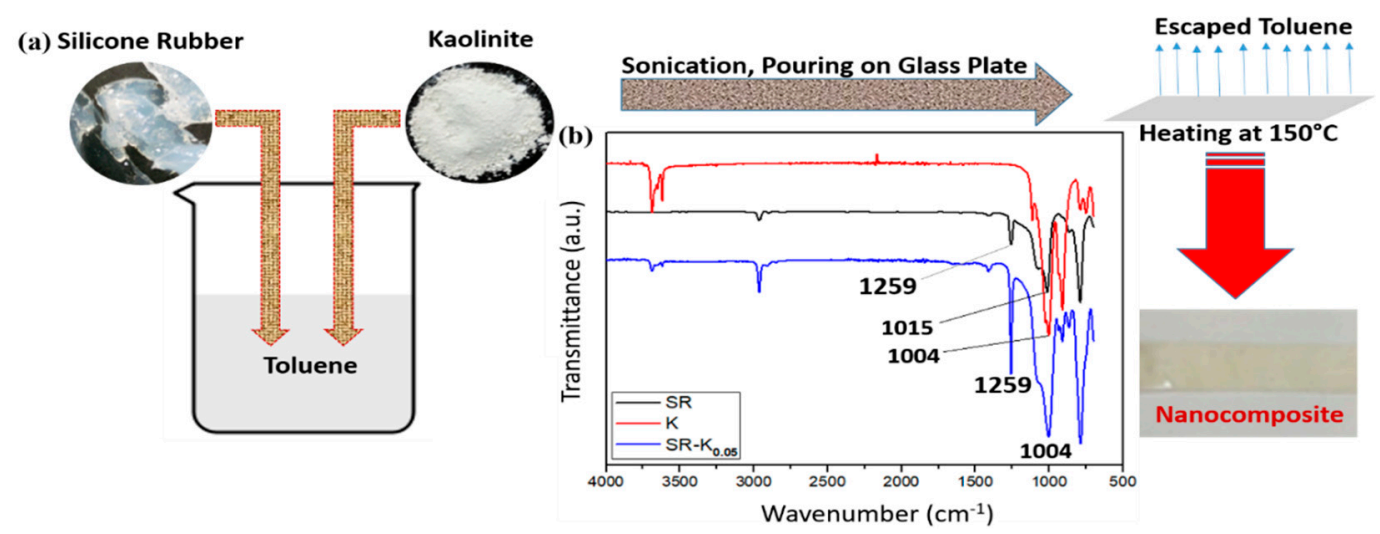

Figure 1. (a) A simplified scheme for NCP preparation (loading of kaolinite led to the formation of optically opaque composite films), (b) FTIR spectra of SR, K, and SR- $\mathrm{K}_{0.05}$ (only the significant peaks are highlighted for comparison purpose). The characteristic absorption band at $1015 \mathrm{~cm}^{-1}$ (SR) overlapped with $1004 \mathrm{~cm}^{-1}(\mathrm{~K})$ and broadened, indicating surface chemical interaction between filler and matrix.

\subsection{FTIR Analysis}

The variation in surface chemistry of SR due to kaolinite loading was well-illustrated via transmission FTIR. The absorbance of various functional groups presents in SR and kaolinite is 
thoroughly discussed in S1. Comparison of FTIR spectra (Figure 1b) suggests that the characteristic peaks for both SR and kaolinite were present in composite $\left(\mathrm{SR}-\mathrm{K}_{0.05}\right)$. The characteristic peak at $1015 \mathrm{~cm}^{-1}$ (Si-O-Si) for SR was submerged with the peak at $1004 \mathrm{~cm}^{-1}$ in SR-K $\mathrm{K}_{0.05}$ and was intensified, which is predicted to occur due to the hydrogen bond formation between the polar hydroxyl groups $(\mathrm{OH})$ inside the kaolinite galleries and siloxane (Si-O-Si) backbone of SR [1].

Dengke et al. also reported the chemical bond formation between nano-layered silicate sheets and room temperature vulcanized SR due to the sharpening of Si-O-Si absorption peak at $1020 \mathrm{~cm}^{-1}$ [31]. The bending vibration at $1259 \mathrm{~cm}^{-1}$ for $\mathrm{Si}-\mathrm{CH}_{3}$ in SR was also significantly intensified in SR-K $\mathrm{K}_{0.05}$, which provides additional support for the variation in surface chemistry of SR due to kaolinite incorporation.

\subsection{XRD Analysis}

As depicted in Figure 2a, the starting kaolinite showed well-defined reflections at $2 \theta$ value 12.37 and $24.87^{\circ}$. Other peaks corresponding to higher $2 \theta$ values were also detected in the XRD pattern. However, the characteristic peaks of kaolinite were absent in SR-K $\mathrm{K}_{0.05}$ after interaction with SR. Ismail et al. reported that the crystalline structure of LS in rubber is revealed with small amount of clay [1]. Therefore, the disappearance of characteristic peaks is significant, which indicates the possibility for the formation of exfoliated NCP in which individual kaolinite nanosheets were randomly oriented (without any periodicity) in the SR matrix [1,32]. Ismail et al. also reported the high exfoliation of natural MMT in SR at very low filler loading (4-8 parts per hundred rubber by weight) [1]. In this research, similar results were observed at $5 \%(w / w)$ kaolinite loading (Figure 2a). In the exfoliated $\mathrm{NCP}$, the separation of clay layers into single platelets in SR matrix is believed to occur due to strong hydrogen bond formation between the polar $\mathrm{OH}$ of kaolinite and siloxane backbone ( $\mathrm{Si}-\mathrm{O}-\mathrm{Si}$ ) of rubber, which was sufficient to overcome the attractive forces holding the clay layers together [1]. The exfoliated nanosheets with higher aspect ratios were expected to improve their compatibility with rubber matrix leading to the enhancement of engineering properties.

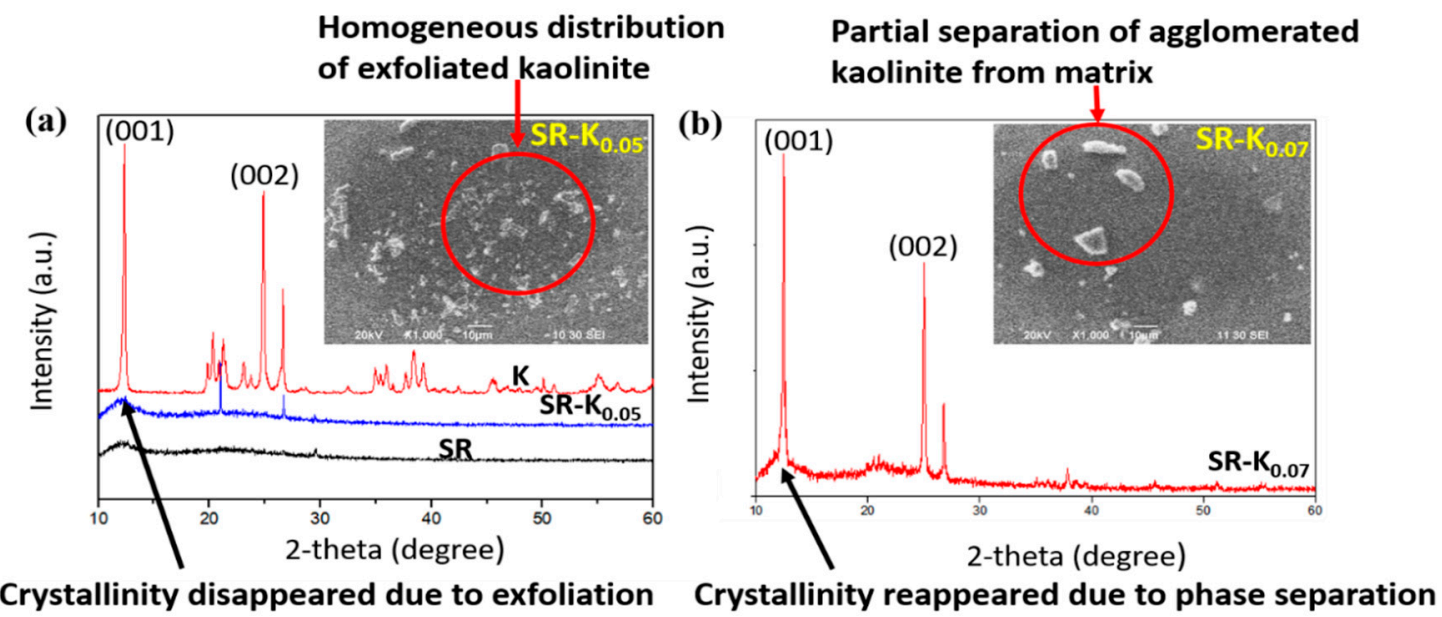

Figure 2. (a) XRD patterns of $S R, K$, and $S R-K_{0.05}$ (Inset shows the SEM micrograph of SR-K 0.05 with scale bar of $10 \mu \mathrm{m}$. The morphological feature and disappearance of crystallinity indicates exfoliation of kaolinite); (b) XRD pattern of SR-K $\mathrm{K}_{0.07}$ (Inset shows the SEM micrograph of SR-K $\mathrm{K}_{0.07}$ with scale bar of $10 \mu \mathrm{m}$. Morphology and characteristic XRD peaks strongly support agglomeration and phase separation of kaolinite from the matrix.).

\subsection{SEM Analysis}

Mechanical performance of composites is greatly affected by the morphology [33]. In this study, morphological features of SR and NCPs were investigated via SEM technique. The control SR film displayed a smooth, uniform, and flat surface having no detectable pores, cracks, and voids (Figure S1). However, incorporation of kaolinite brought variation in surface morphology, as illustrated in Figure 2a. 
The homogeneous distribution of exfoliated nanosheets throughout the SR matrix is evident in Figure 2a, which strongly supports the XRD data. This type of even distribution might occur due to the strong interfacial chemical interaction between kaolinite filler and SR matrix. The uniform distribution of fillers is highly desirable for engineering applications of advanced polymer NCPs. In this study, kaolinite was homogeneously dispersed in the rubber matrix by sonication for $30 \mathrm{~min}$. It has been widely reported in literature that ultrasonication ensures the uniform dispersion and exfoliation of LS in the polymer matrix. Horrocks et al. observed improved dispersion of nanoclay in polymer matrix after ultrasound treatment [34]. Kaboorani et al. reported ultrasonication as an efficient strategy for dispersing nanoclay in polyvinyl acetate [35]. Ultrasonication plays a predominant role in the formation of exfoliated NCP by assisting the migration/diffusion of polymer into the interlayer galleries of LS, which push apart silicate layers. Due to ultrasonication, alternating high-pressure and low-pressure waves are created in the liquid medium leading to the formation, growth, and violent collapse of a large number of vacuum microbubbles in a very short time (microseconds). This phenomenon is called cavitation, which results in the deagglomeration of nanometer size materials by causing high-speed impinging liquid jets and strong hydrodynamic shear-forces [35]. Apart from nanoclay, the uniform dispersion of other nanomaterials through ultrasonication has also been reported in literature [36,37].

\subsection{Mechanical Properties}

As illustrated in Figure 3, the unfilled SR film showed inferior mechanical performance $\left(T_{s}, Y_{s}\right.$, and $\mathrm{E}_{\mathrm{b}}$ ) due to the low melting point $(\sim 233 \mathrm{~K})$ for which a strain-induced crystallization could not be readily provided [38]. However, a substantial improvement in mechanical properties was found after the gradual addition of kaolinite up to $5 \%(w / w)$. The progressive improvement of $\mathrm{T}_{\mathrm{s}}$ with kaolinite loading, as illustrated in Figure 3a, could be attributed to the possible strain-induced alignment of the kaolinite nanolayers in the SR matrix [39] together with strong hydrogen bond formation between fillers and matrix [40]. The high aspect ratio of the exfoliated-clay platelets led to the significant load transfer from matrix to filler resulting in a higher value of $\mathrm{T}_{\mathrm{s}}$ in SR-K $\mathrm{K}_{0.05}$ [1].

As shown in Figure 3c, the elongation at the break showed marvelous improvement with the addition of kaolinite It is evident from Figure 3c that unfilled SR film showed an $E_{b}$ value of $387 \%$, whereas SR- $\mathrm{K}_{0.05}$ showed $577 \%$. This dramatic improvement in $\mathrm{E}_{\mathrm{b}}$ might be attributed to the following factors: (1) the well dispersion of nanosheets in the SR matrix, which delocalized the stress by the absorption and dispersion of the applied load, (2) the lubricating effect of SR at the kaolinite surface which enhanced slipping of clay nanolayers in the matrix, and (3) the plasticizing effect of SR [33]. The progressive increase in mechanical performance with the gradual addition of kaolinite (up to $5 \mathrm{wt} \%$ ) may be attributed to the successive and effective binding of filler with the matrix at the interface. Similar effect has been reported with NCPs based on other kind of nanoclay [41]. However, it is evident from Figure $3 \mathrm{a}-\mathrm{c}$ that as the clay content exceeded $5 \%(w / w)$, the values of Ts, Ys, and Eb decreased gradually. Therefore, it can be said that the highest mechanical performance can be obtained only at $5 \%(w / w)$ kaolinite loading, which appears to be the critical kaolinite content for the fabricated NCPs. This critical content is well-supported by the previous studies, where numerous researchers reported that SR-clay NCP films showed best mechanical performance at low filler loading $[1,24,26,29,31,33,42]$. It has been reported in the literature that superior mechanical and thermal properties are found with exfoliated and intercalated NCPs compared to conventional composites [43]. As supported by the XRD and SEM of SR-K $\mathrm{K}_{0.05}$ (Figure 2a), it can be said that the homogeneous distribution of exfoliated nanosheets throughout the matrix together with high filler adhesion at the interface was achieved at this critical kaolinite content, which ultimately resulted in the fabrication of high performance NCPs. The exfoliated nanosheets having a high available surface area can easily interact with the polymeric chains, leading to the formation of physically cross-linked network in which nanolayers act as a physical cross-linking junctions [26]. Here, $5 \%(w / w)$ kaolinite was sufficient to cover the SR matrix completely. At this critical kaolinite loading, the hydrogen bond formation led to effective interfacial interaction between filler and matrix while further addition of kaolinite negatively affected 
this interaction, which ultimately compromised mechanical performance. Composites containing more than $5 \%(w / w)$ kaolinite contained excess and unwrapped kaolinite having high surface energy profile. As a result, the electrostatic force of attraction among the excess particles during mixing led to the partial separation of fillers from the rubber matrix in the form of agglomerates. This separation was detected in the SEM images of SR-K $\mathrm{K}_{0.07}$ (Figure $2 \mathrm{~b}$ ). The crystalline geometry of these aggregates

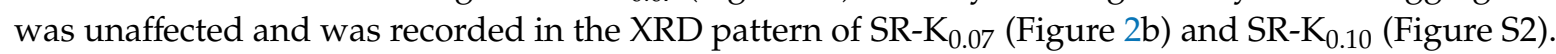
As illustrated in Figure $2 b$, the presence of characteristic reflections of kaolinite in $S R-K_{0.07}$ provides additional support for the partial separation of fillers from the rubber matrix. This partial separation weakened the matrix junctions and led to decreased mechanical performance (Table 2). The calculated standard deviations of the data for investigated mechanical properties are presented in Table S1.
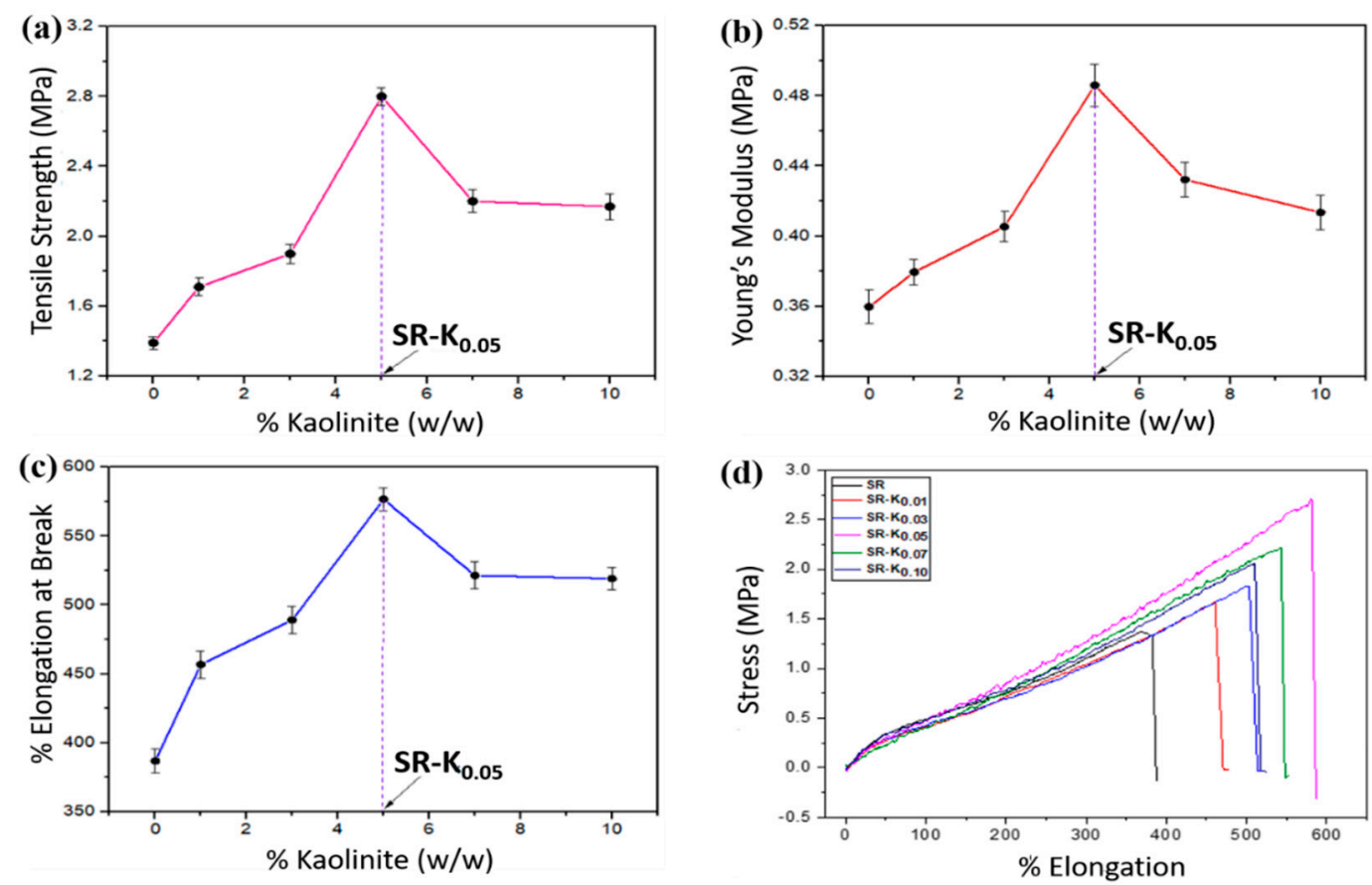

Figure 3. Effect of kaolinite content on the (a) tensile strength, (b) Young's modulus, and (c) percent elongation at break. The mechanical performance increased gradually with the addition of kaolinite up to $5 \%(w / w)$. After that there was a decline in the performance due to the agglomeration and phase separation of kaolinite from the SR matrix. (d) Stress vs. percent elongation curves.

Table 2. Summary of investigated mechanical properties of SR and NCPs.

\begin{tabular}{cccc}
\hline Film Code & Tensile Strength (MPa) & Young's Modulus (MPa) & Elongation at Break (\%) \\
\hline SR & $1.39 \pm 0.034$ & $0.36 \pm 0.009$ & $386.89 \pm 8.862$ \\
SR-K 0.01 & $1.71 \pm 0.049$ & $0.38 \pm 0.007$ & $456.81 \pm 9.792$ \\
SR-K 0.03 & $1.99 \pm 0.054$ & $0.41 \pm 0.008$ & $489.07 \pm 10.098$ \\
SR-K 0.05 & $2.80 \pm 0.051$ & $0.49 \pm 0.011$ & $576.67 \pm 8.244$ \\
SR-K $_{0.07}$ & $2.20 \pm 0.065$ & $0.43 \pm 0.009$ & $521.44 \pm 9.977$ \\
SR-K $_{0.10}$ & $2.17 \pm 0.074$ & $0.41 \pm 0.009$ & $519.11 \pm 8.318$ \\
\hline
\end{tabular}

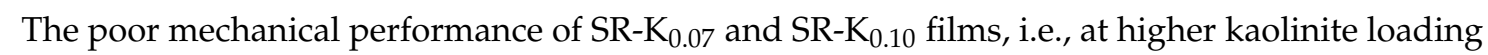
( $>5 \mathrm{wt} \%$ ) could be attributed to the poor dispersion and low filler adhesion at the interface with SR matrix [33]. Finally, the representation in Figure 3d demonstrates the linear relationship between applied stress and percent elongation for the fabricated NCP films. 


\subsection{Thermal Stability}

Many engineering applications require higher thermal stability of NCPs. Therefore, in this study, the thermal properties of the fabricated NCP films were investigated under a nitrogen atmosphere. To adequately explain the insights into the degradation, various values, such as $T_{10}, T_{50}$, and $R_{800}$, as related to thermal stability, were recorded. SR is one of the most heat-resistant rubbers, however, it degrades into volatile cyclic silicates at a temperature above $300{ }^{\circ} \mathrm{C}[29,44]$. Due to high bond dissociation energy of $\mathrm{Si}-\mathrm{O}$ compared to $\mathrm{Si}-\mathrm{C}$, the degradation of SR starts with alkyl groups followed by siloxane backbone [45]. As illustrated in Figure 4a, 86\% of SR decomposed before the temperature reached $500{ }^{\circ} \mathrm{C}$. However, it was carefully observed that the addition of a small amount of kaolinite led to the substantial improvement in the thermal stability of the fabricated NCPs.
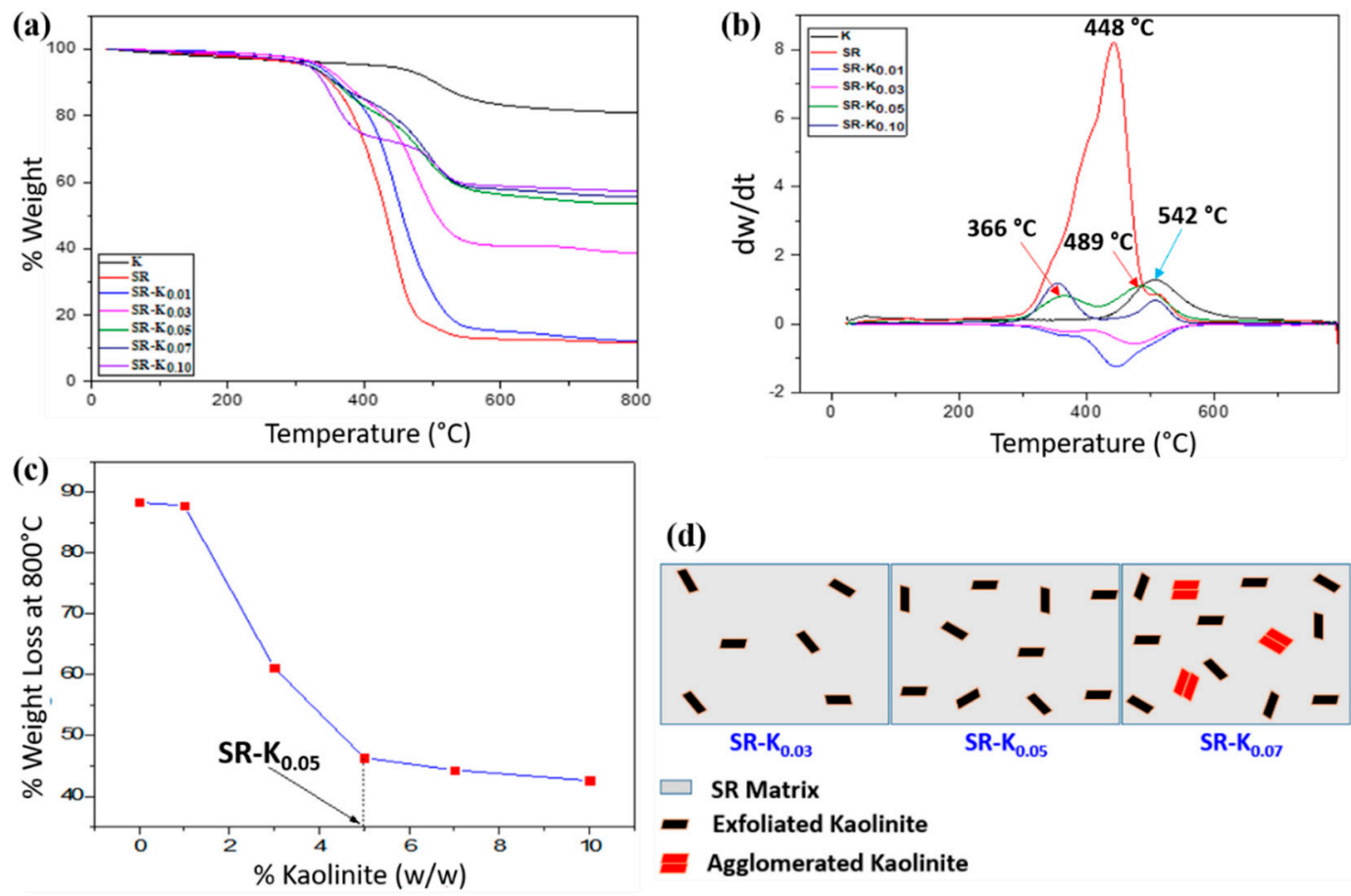

(d)

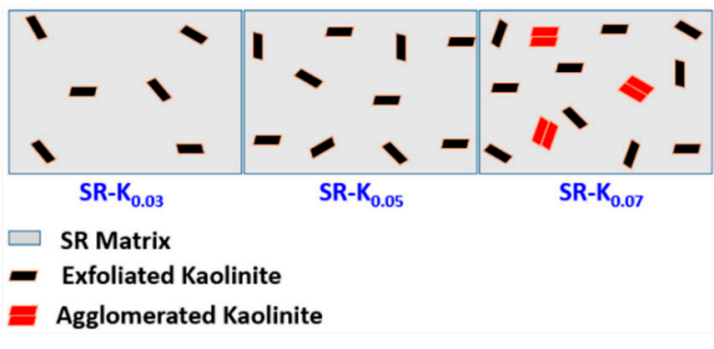

Figure 4. (a) Thermogravimetric analyzer (TGA) thermograms of SR and NCPs under nitrogen flow, (b) derivative thermogravimetric (DTG) curves illustrating specific decomposition temperatures, (c) effect of kaolinite loading on percent weight loss of SR and NCPs (The weight loss profile indicates that addition of small amount of $\mathrm{K}$, i.e., $5 \mathrm{wt} \%$ dramatically improved the thermal stability.), (d) mechanistic view for variation in performance $\left(\mathrm{SR}-\mathrm{K}_{0.03}\right.$ : Matrix is partially covered requiring more kaolinite, $\mathrm{SR}-\mathrm{K}_{0.05}$ : Matrix is completely covered with no excess kaolinite, $\mathrm{SR}-\mathrm{K}_{0.07}$ : Excess kaolinite leads to phase separation and agglomeration).

Unfilled SR film showed onset degradation temperature $\left(\mathrm{T}_{\text {onset }} / \mathrm{T}_{10}\right)$ at $351{ }^{\circ} \mathrm{C}$, while this value significantly shifted to a higher temperature for all of the NCPs. The temperature for $50 \%$ mass loss, i.e., $\mathrm{T}_{50}$ (as a measure of mid-point of degradation) was recorded at $431{ }^{\circ} \mathrm{C}$ for unfilled SR film, but this value also shifted to $456^{\circ} \mathrm{C}$ and $506^{\circ} \mathrm{C}$, respectively, for SR-K $\mathrm{K}_{0.01}$ and SR-K $\mathrm{K}_{0.03}$. Apart from this, the char residue at $800{ }^{\circ} \mathrm{C}$, i.e., $\mathrm{R}_{800}$ also increased progressively with the gradual addition of kaolinite The values of $T_{10}, T_{50}$, and $R_{800}$ are summarized in Table 3 .

The enhanced thermal stability of the NCPs may be attributed to the effective filler-matrix interaction, which prevented the segmental motion of the macromolecules [26]. The rate of diffusion of the volatile decomposition products out of the bulk was reduced by the addition of thermally stable kaolinite, which increased the effective path length for the diffusion of this products by creating a tortuous pathway [46]. Uniformly dispersed kaolinite acted as a barrier to the passage of the volatile pyrolized products of SR due to their entrapment into the nanoparticles' lumen [47,48]. The derivative 
thermogravimetric (DTG) curves, shown in Figure $4 b$, clearly illustrates various degradation steps in the NCPs due to heat treatment. The individual degradation steps in NCPs could be more easily understood from DTG curves than TG curves alone. The DTG peaks more accurately indicate characteristic decomposition temperatures of different components [49]. Neat SR displayed single-step degradation with $\mathrm{T}_{\max }$ (temperature of the peak maximum) value of $448^{\circ} \mathrm{C}$. In the case of kaolinite, the transformation from crystalline kaolinite to amorphous metakaolinite, due to dehydroxylation, was recorded at $542{ }^{\circ} \mathrm{C}\left(\mathrm{T}_{\max }\right)$. However, two-step degradation was recorded in the case of SR-K $\mathrm{K}_{0.05}$ with $\mathrm{T}_{\max }$ value of $366^{\circ} \mathrm{C}$ and $489^{\circ} \mathrm{C}$, respectively. The two-step thermal degradation in SR-based composites has also been reported by Shi et al. [50]. It is interesting to note that in this study, the peak position was shifted from $448{ }^{\circ} \mathrm{C}$ in SR to $489^{\circ} \mathrm{C}$ in SR-K $\mathrm{K}_{0.05}$. Besides, peak height was significantly lowered. Therefore, phase transformation in SR was significantly restricted, as well as delayed, due to the introduction of kaolinite nanofillers.

Table 3. Comparison of TGA data of unfilled SR with SR-K NCPs.

\begin{tabular}{cccc}
\hline Film Code & $\mathbf{T}_{\mathbf{1 0}}\left({ }^{\circ} \mathbf{C}\right)$ & $\mathbf{T}_{\mathbf{5 0}}\left({ }^{\circ} \mathbf{C}\right)$ & $\mathbf{R}_{\mathbf{8 0 0}}\left({ }^{\circ} \mathbf{C}\right)$ \\
\hline SR & 351 & 431 & 11.72 \\
SR-K $_{0.01}$ & 355 & 456 & 12.22 \\
SR-K $_{0.03}$ & 360 & 506 & 38.84 \\
SR-K $_{0.05}$ & 362 & - & 53.65 \\
SR-K $_{0.07}$ & 367 & - & 55.66 \\
SR-K $_{0.10}$ & 376 & - & 57.38 \\
\hline
\end{tabular}

TGA also helped us identify the optimum filler content. For finding the critical kaolinite loading, percent weight loss at $800{ }^{\circ} \mathrm{C}$ was plotted against the kaolinite content (Figure 4c). It is clear from this plot that unfilled SR film showed $88.28 \%$ weight loss at $800^{\circ} \mathrm{C}$, whereas this loss decreased significantly to $46.35 \%$ at $5 \%(w / w)$ kaolinite loading. Therefore, only $5 \%(w / w)$ addition of kaolinite prevented approximately $42 \%$ loss of SR. It was undoubtedly a remarkable improvement in the thermal stability. Kong et al. reported only 8.5\% residue of SR-clay composite at 7\% filler loading [26], whereas Mishra et al. reported $33 \%$ residue at $10 \%$ filler loading [24]. In this study, $53.65 \%$ residue is reported at only $5 \%$ filler loading. This comparison indicates that this study was more successful in fabricating thermally stable NCPs. However, no significant effect on thermal stability was observed with the further addition of kaolinite Therefore, it can be concluded that thermally stable and mechanically superior NCPs can be fabricated by doping only $5 \%(w / w)$ kaolinite in SR matrix. This statement is well supported by XRD and SEM analysis (discussed earlier). A graphical representation in Figure 4d demonstrates a simplified mechanism for the superior thermal and mechanical properties of NCP at $5 \%(w / w)$ kaolinite loading.

\subsection{Solvent Effect}

The fabricated films were soaked in four common polar solvents (water, DMSO, DMF, and acetic acid) for $24 \mathrm{~h}$ at $25^{\circ} \mathrm{C}$ and no significant weight change was noticed after this long period (Figure S3). This observation indicates that both SR and NCPs were chemically resistant against the applied solvents. The freely rotating nonpolar methyl groups placed on the exterior of the helical structure of silicone macromolecule might explain the observed repellency properties towards the applied polar solvents. However, the immersion of the films (SR and SR- $\mathrm{K}_{0.05}$ ) in non-polar toluene showed different results, as displayed in Figure 5a. Unfilled SR film showed $\sim 19 \%$ weight loss after $4 \mathrm{~h}$ of soaking at $25{ }^{\circ} \mathrm{C}$, whereas only $\sim 4 \%$ weight loss was calculated for SR- $\mathrm{K}_{0.05}$ at the same condition. It was a phenomenal improvement in the chemical resistance property of the NCP films.

The inherent property of unfilled SR was not probably resilient enough to resist the action of toluene, whereas kaolinite could probably prevent the separation of silicone macromolecules from the matrix by forming modified and robust filler-matrix interface. Therefore, the introduction of kaolinite 
played a remarkable role in the fabrication of high performance NCPs. The toluene uptake capacity of both SR and SR- $\mathrm{K}_{0.05}$ was also investigated at $25^{\circ} \mathrm{C}$. After $4 \mathrm{~h}$ of soaking in toluene, unfilled SR film showed $\sim 170 \%$ swelling, while $\sim 225 \%$ swelling was observed in the case of $\mathrm{SR}-\mathrm{K}_{0.05}$ (Figure $5 \mathrm{~b}$ ). Here, it is predicted that the helical structure of the macromolecule was the underlying factor for different solvent uptake by SR and SR- $\mathrm{K}_{0.05}$. The penetration of toluene into the matrix through the coiled macromolecular structure could be arduous. The incorporation of kaolinite probably altered this helical framework, thereby creating sufficient scope for toluene to penetrate into the matrix. As a result, SR-K $\mathrm{K}_{0.05}$ displayed a higher degree of swelling than unfilled SR film.
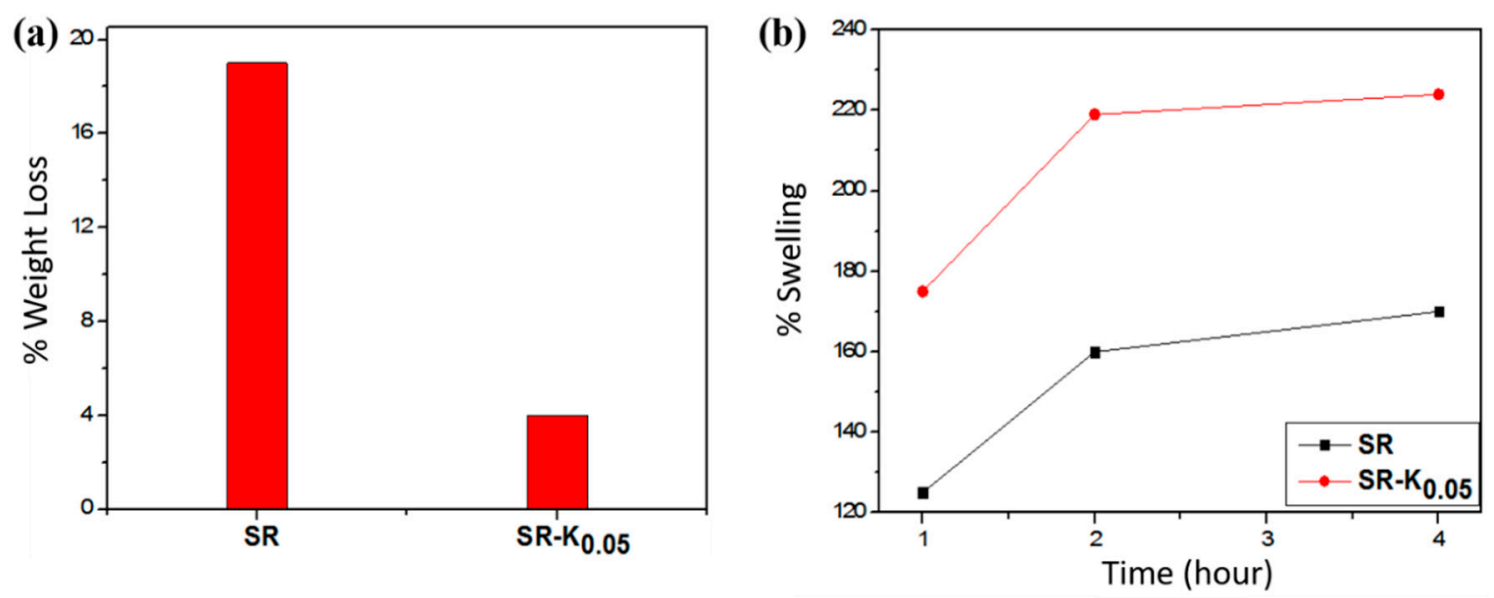

Figure 5. (a) Effect of toluene on percent weight loss (SR-K $\mathrm{K}_{0.05}$ showed reduced weight loss compared with unfilled SR); (b) degree of swelling vs. time (SR-K $\mathrm{K}_{0.05}$ showed comparatively better swelling behavior in toluene than SR.).

\section{Conclusions}

In this study, NCPs were successfully prepared with varying kaolinite content, using a simple solvent casting method. The NCP films displayed superior mechanical and thermal properties compared to unfilled SR films due to the efficient incorporation of kaolinite The best mechanical and thermal performance was found at $5 \%(w / w)$ kaolinite loading, which was firmly supported by SEM and XRD observation. The fabricated NCP films showed noticeably improved resistance towards weight loss when immersed in toluene compared to unfilled SR film. The notable improvement in mechanical, thermal, and chemical properties strongly imply the fabrication of high-performance composite. This study indicates that naturally available kaolinite has a great potential for the advancement of research in materials science. The NCP films fabricated from nonhazardous kaolinite are expected to replace the existing expensive films used worldwide for numerous applications. Finally, the study opens new doors for developing SR-based technology by incorporating naturally available and environment-friendly kaolinite.

Supplementary Materials: The following are available online at http://www.mdpi.com/2504-477X/3/2/50/s1, S1: FTIR analysis of SR and kaolinite; Figure S1: SEM microphotograph of SR; Figure S2: XRD pattern of SR-K $\mathrm{K}_{0.10}$; Table S1: Calculated standard deviations of the observed data for investigated mechanical properties; Figure S3: Effect of solvents on weight loss of SR and SR-K $\mathrm{K}_{0.05}$.

Author Contributions: Conceptualization, S.M.S., M.A. and S.C.D.; Data curation, A.M.Z.; Formal analysis, A.M.Z., S.C.D., M.M.R. and M.S.; Funding acquisition, S.M.S. and S.C.D.; Investigation, A.M.Z.; Methodology, A.M.Z., S.C.D., M.A. and S.M.S.; Project administration, S.M.S. and S.C.D.; Resources, S.M.S.; Supervision, S.M.S., M.A. and S.C.D.; Validation, A.M.Z.; Visualization, A.M.Z.; Writing-original draft, S.C.D. and A.M.Z.; Writing-review \& editing, A.M.Z., S.C.D., M.M.R., M.S., M.A. and S.M.S.

Funding: This research was funded by Ministry of Science and Technology (Bangladesh), grant number 39.00.0000.09.06.79.2018-19/309 (EAS-8). 
Acknowledgments: The authors are grateful to the Centre for Advanced Research in Sciences (CARS), University of Dhaka, Bangladesh for providing partial analytical support. The authors also thank Bangladesh Council of Scientific and Industrial Research (BCSIR) for providing facilities to investigate mechanical properties.

Conflicts of Interest: The authors declare no conflict of interest.

\section{References}

1. Ismail, N.N.; Ansarifar, A.; Song, M. Preparation and characterization of high-performance exfoliated montmorillonite/silicone rubber nanocomposites with enhanced mechanical properties. Polym. Eng. Sci. 2013, 53, 2603-2614. [CrossRef]

2. Hu, Y.; Mei, R.; An, Z.; Zhang, J. Silicon rubber/hollow glass microsphere composites: Influence of broken hollow glass microsphere on mechanical and thermal insulation property. Compos. Sci. Technol. 2013, 79, 64-69. [CrossRef]

3. Gonzalez-Perez, G.; Burillo, G.; Ogawa, T.; Avalos-Borja, M. Grafting of styrene and 2-vinylnaphthalene onto silicone rubber to improve radiation resistance. Polym. Degrad. Stab. 2012, 97, 1495-1503. [CrossRef]

4. Fang, W.; Lai, X.; Li, H.; Chen, W.; Zeng, X.; Zhang, L.; Yang, S. Effect of urea-containing anti-tracking additive on the tracking and erosion resistance of addition-cure liquid silicone rubber. Polym. Test. 2014, 37, 19-27. [CrossRef]

5. Bortz, D.R.; Merino, C.; Martin-Gullon, I. Carbon nanofibers enhance the fracture toughness and fatigue performance of a structural epoxy system. Compos. Sci. Technol. 2011, 71, 31-38. [CrossRef]

6. Zhang, X.; Zhang, Q.; Zheng, J. Effect and mechanism of iron oxide modified carbon nanotubes on thermal oxidative stability of silicone rubber. Compos. Sci. Technol. 2014, 99, 1-7. [CrossRef]

7. Van den Ende, D.A.; Gubbels, G.H.M. Fracture toughness of hydroxide catalysis bonds between silicon carbide and zerodur low thermal expansion glass-ceramic. Mater. Chem. Phys. 2014, 143, 1236-1242. [CrossRef]

8. Pramanik, M.; Srivastava, S.K.; Samantaray, B.K.; Bhowmick, A.K. Rubber-clay nanocomposite by solution blending. J. Appl. Polym. Sci. 2003, 87, 2216-2220. [CrossRef]

9. LeBaron, P.C.; Pinnavaia, T.J. Clay nanolayer reinforcement of a silicone elastomer. Chem. Mater. 2001, 13, 3760-3765. [CrossRef]

10. Burnside, S.D.; Giannelis, E.P. Nanostructure and properties of polysiloxane-layered silicate nanocomposites. J. Polym. Sci. Part B Polym. Phys. 2000, 38, 1595-1604. [CrossRef]

11. Guo, J.; Chen, X.; Zhang, Y. Improving the mechanical and electrical properties of ceramizable silicone rubber/halloysite composites and their ceramic residues by incorporation of different borates. Polymers 2018, 10, 388. [CrossRef]

12. Karami, Z.; Jazani, O.M.; Navarchian, A.H.; Karrabi, M.; Vahabi, H.; Saeb, M.R. Well-cured silicone/halloysite nanotubes nanocomposite coatings. Prog. Org. Coat. 2019, 129, 357-365. [CrossRef]

13. Mishra, R.M.; Rai, J.S.P. Compatibilizing effect of halloysite nanotubes on polyetherimide/silicone rubber blend-based nanocomposites. Polym.-Plast. Technol. Mater. 2019, 58, 341-347. [CrossRef]

14. Sanchez-Hidalgo, R.; Blanco, C.; Menendez, R.; Verdejo, R.; Lopez-Manchado, M.A. Multifunctional silicone rubber nanocomposites by controlling the structure and morphology of graphene material. Polymers 2019, 11, 449. [CrossRef]

15. Liang, W.; Ge, X.; Ge, J.; Li, T.; Zhao, T.; Chen, X.; Song, Y.; Cui, Y.; Khan, M.; Ji, J.; et al. Reduced graphene oxide embedded with MQ silicone resin nano-aggregates for silicone rubber composites with enhanced thermal conductivity and mechanical performance. Polymers 2018, 10, 1254. [CrossRef]

16. Chen, K.; Kang, M.; Lu, A.; Chen, L.; Song, L.; Sun, R. Visualization of silica dispersion states in silicone rubber by fluorescent labeling. J. Mater. Sci. 2019, 54, 5149-5159. [CrossRef]

17. Xue, Y.; Li, X.; Wang, H.; Zhao, F.; Zhang, D.; Chen, Y. Improvement in thermal conductivity of through-plane aligned boron nitride/silicone rubber composites. Mater. Des. 2019, 165, 107580. [CrossRef]

18. Tamore, M.S.; Ratna, D.; Mishra, S.; Shimpi, N.G. Effect of functionalized multi-walled carbon nanotubes on physicomechanical properties of silicone rubber nanocomposites. J. Compos. Mater. 2019. [CrossRef]

19. Vaimakis-Tsogkas, D.T.; Bekas, D.G.; Giannakopoulou, T.; Todorova, N.; Paipetis, A.S.; Barkoula, N.M. Effect of $\mathrm{TiO}_{2}$ addition/coating on the performance of polydimethylsiloxane-based silicone elastomers for outdoor applications. Mater. Chem. Phys. 2019, 223, 366-373. [CrossRef] 
20. Guo, J.; Wang, X.; Jia, Z.; Wang, J.; Chen, C. Nonlinear electrical properties and field dependency of BST and nano-ZnO-doped silicone rubber composites. Molecules 2018, 23, 3153. [CrossRef]

21. Han, R.; Wang, Z.; Zhang, Y.; Niu, K. Thermal stability of $\mathrm{CeO}_{2}$ /graphene/phenyl silicone rubber composites. Polym. Test. 2019, 75, 277-283. [CrossRef]

22. Hafiz, M.; Fairus, M.; Mariatti, M.; Kamarol, M. A Comparative study on electrical tree growth in silicone rubber containing nanoalumina and halloysite nanoclay. IEEE Access 2019, 7, 24452-24462. [CrossRef]

23. Pinnavaia, T.J. Intercalated clay catalysts. Science 1983, 220, 365-371. [CrossRef] [PubMed]

24. Mishra, S.; Shimpi, N.G.; Mali, A.D. Surface modification of montmorillonite (MMT) using column chromatography technique and its application in silicone rubber nanocomposites. Macromol. Res. 2012, 20, 44-50. [CrossRef]

25. Kim, E.S.; Kim, E.J.; Lee, T.H.; Yoon, J.S. Clay modification and its effect on the physical properties of silicone rubber/clay composites. J. Appl. Polym. Sci. 2012, 125, E298-E304. [CrossRef]

26. Kong, Q.; Hu, Y.; Song, L.; Wang, Y.; Chen, Z.; Fan, W. Influence of Fe-MMT on crosslinking and thermal degradation in silicone rubber/clay nanocomposites. Polym. Adv. Technol. 2006, 17, 463-467. [CrossRef]

27. Lan, T.; Kaviratna, P.D.; Pinnavaia, T.J. Mechanism of clay tactoid exfoliation in epoxy-clay nanocomposites. Chem. Mater. 1995, 7, 2144-2150. [CrossRef]

28. Yoon, J.T.; Jo, W.H.; Lee, M.S.; Ko, M.B. Effects of comonomers and shear on the melt intercalation of styrenics/clay nanocomposites. Polymer 2001, 42, 329-336. [CrossRef]

29. Ma, J.; Yu, Z.Z.; Kuan, H.C.; Dasari, A.; Mai, Y.W. A new strategy to exfoliate silicone rubber/clay nanocomposites. Macromol. Rapid Commun. 2005, 26, 830-833. [CrossRef]

30. EN ISO 1421:1998, Method 1-Strip Test (Tensile Strength and Elongation at Break). Available online: https://www.mecmesin.com/bs-en-iso-1421-1998-rubber-or-plastic-coated-fabrics-determinationof-tensile-strength-and-elongation-at-break (accessed on 10 April 2019).

31. Dengke, C.; Xishan, W.; Lei, L. Research on characterization of RTV silicone rubber/LS (layered silicate) electrical insulation nanocomposites. In Proceedings of the 8th International Conference on Solid Dielectrics, Toulouse, France, 5-9 July 2004; Volume 2, pp. 796-799.

32. Letaief, S.; Leclercq, J.; Liu, Y.; Detellier, C. Single kaolinite nanometer layers prepared by an in-situ polymerization-exfoliation process in the presence of ionic liquids. Langmuir 2011, 27, 15248-15254. [CrossRef]

33. Kaneko, M.L.Q.A.; Romero, R.B.; Gonçalves, M.D.C.; Yoshida, I.V.P. High molar mass silicone rubber reinforced with montmorillonite clay masterbatches: Morphology and mechanical properties. Eur. Polym. J. 2010, 46, 881-890. [CrossRef]

34. Horrocks, A.R.; Kandola, B.; Milnes, G.J.; Sitpalan, A.; Hadimani, R.L. The potential for ultrasound to improve nanoparticle dispersion and increase flame resistance in fibre-forming polymers. Polym. Degrad. Stab. 2012, 97, 2511-2523. [CrossRef]

35. Kaboorani, A.; Riedl, B.; Blanchet, P. Ultrasonication technique: A method for dispersing nanoclay in wood adhesives. J. Nanometer. 2013, 2013, 341897. [CrossRef]

36. Lu, Z.; Hou, D.; Hanif, A.; Hao, W.; Li, Z.; Sun, G. Comparative evaluation on the dispersion and stability of graphene oxide in water and cement pore solution by incorporating silica fume. Cem. Concr. Compos. 2018, 94, 33-42. [CrossRef]

37. Lu, Z.; Hanif, A.; Ning, C.; Shao, H.; Yin, R.; Li, Z. Steric stabilization of graphene oxide in alkaline cementitious solutions: Mechanical enhancement of cement composite. Mater. Des. 2017, 127, 154-161. [CrossRef]

38. Sharaf, M.A.; Kloczkowski, A.; Mark, J.E. Dynamic mechanical losses in filled poly (dimethylsiloxane) networks. Rubber Chem. Technol. 1995, 68, 601-608. [CrossRef]

39. Giannelis, E.P. Polymer layered silicate nanocomposites. Adv. Mater. 1996, 8, 29-35. [CrossRef]

40. Ray, S.S.; Okamoto, M. Polymer/layered silicate nanocomposites: A review from preparation to processing. Prog. Polym. Sci. 2003, 28, 1539-1641.

41. Bertolino, V.; Cavallaro, G.; Lazzara, G.; Merli, M.; Milioto, S.; Parisi, F.; Sciascia, L. Effect of the biopolymer charge and the nanoclay morphology on nanocomposite materials. Ind. Eng. Chem. Res. 2016, 55, 7373-7380. [CrossRef]

42. Wang, S.; Long, C.; Wang, X.; Li, Q.; Qi, Z. Synthesis and properties of silicone rubber/organomont- morillonite hybrid nanocomposites. J. Appl. Polym. Sci. 1998, 69, 1557-1561. [CrossRef] 
43. Bokobza, L. Elastomeric composites. I. Silicone composites. J. Appl. Polym. Sci. 2004, 93, 2095-2104. [CrossRef]

44. Grassie, N.; Macfarlane, I.G. The thermal degradation of polysiloxanes-I. Poly (dimethylsiloxane). Eur. Polym. J. 1978, 14, 875-884. [CrossRef]

45. Zhao, X.W.; Zang, C.G.; Wen, Y.Q.; Jiao, Q.J. Thermal and mechanical properties of liquid silicone rubber composites filled with functionalized graphene oxide. J. Appl. Polym. Sci. 2015, 132, 42582. [CrossRef]

46. Chen, G.; Liu, S.; Chen, S.; Qi, Z. FTIR spectra, thermal properties, and dispersibility of a polystyrene/montmorillonite nanocomposite. Macromol. Chem. Phys. 2001, 202, 1189-1193. [CrossRef]

47. Makaremi, M.; Pasbakhsh, P.; Cavallaro, G.; Lazzara, G.; Aw, Y.K.; Lee, S.M.; Milioto, S. Effect of morphology and size of halloysite nanotubes on functional pectin bio-nanocomposites for food packaging applications. ACS Appl. Mater. Interfaces 2017, 9, 17476-17488. [CrossRef] [PubMed]

48. Bertolino, V.; Cavallaro, G.; Lazzara, G.; Milioto, S.; Parisi, F. Halloysite nanotubes sandwiched between chitosan layers: Novel bio-nanocomposites with multilayer structures. New J. Chem. 2018, 42, 8384-8390. [CrossRef]

49. Földvári, M. Handbook of Thermogravimetric System of Minerals and Its Use in Geological Practice; Geological Institute of Hungary: Budapest, Hungary, 2011; Volume 213.

50. Shi, Y.; Gao, X.; Zhang, D.; Liu, Y.; Huang, G. Synthesis and thermal properties of room temperature vulcanized (RTV) silicone rubber using polyhedral oligomeric silsesquioxane (POSS) as a cross linking agent. RSC Adv. 2014, 4, 41453-41460. [CrossRef]

(C) 2019 by the authors. Licensee MDPI, Basel, Switzerland. This article is an open access article distributed under the terms and conditions of the Creative Commons Attribution (CC BY) license (http://creativecommons.org/licenses/by/4.0/). 